\title{
Stylopharyngeus Muscle
}

National Cancer Institute

\section{Source}

National Cancer Institute. Stylopharyngeus Muscle. NCI Thesaurus. Code C33639.

A long, thin pharyngeal muscle, which originates on the styloid process with some fibers attaching to the constrictors and the lateral glossoepiglottic fold, while others attach to the thyroid cartilage; it functions to elevate the pharynx and larynx. 